\title{
Reflexiones sobre el acontecimiento de la expectación en el teatro contemporáneo argentino.
}

\author{
Anabel Edith Paoletta \\ TECC- Facultad de Arte- UNICEN \\ apaoletta@arte.unicen.edu.ar \\ Artículo bajo licencia Creative Commons \\ Atribución 4.0 Internacional (CC BY 4.0) \\ ENVIADO: 2021-04-03 \\ ACEPTADO: $2021-11-16$
}

\section{RESUMEN}

El presente artículo pretende elaborar un análisis sobre el sub acontecimiento de la expectación en la obra Todo lo que está a mi lado de Fernando Rubio. El estudio se aborda desde las perspectivas que ofrecen las categorías de teatro posdramático y performance art, ya que ubican al espectador en un rol activo, que se asume como productor de la obra de arte. En este sentido se desarrolla un recorrido en relación al concepto de percepción del sujeto en el campo del arte teatral para discutirlo en vínculo estrecho con la experiencia artística estudiada.

Palabras CLAVE

Teatro contemporáneo. Teatro itinerante. Performance. Participación del público. Percepción.

\section{RESUMO}

Este artigo tem como objetivo elaborar uma análise sobre 0 subevento de expectativa na obra Tudo o que está ao meu lado de Fernando Rubio. 0 estudo é abordado a partir das perspectivas oferecidas pelas categorias teatro pós-dramático e arte performática, uma vez que colocam o espectador em um papel ativo, que se assume como produtor da obra de arte. Nesse sentido, desenvolve-se um percurso em relação ao conceito de percepção do sujeito no campo da arte teatral para discuti-lo em estreita ligação com a experiência artística estudada.

\section{PALAVRAS-CHAVE}

Teatro contemporâneo. Teatro itinerante. Performance. Participação pública. Percepção.

\section{ABSTRACT}

This paper aims to elaborate an analysis on the sub-event of expectation in the work Everything that is next to me by Fernando Rubio. The study is approached from the perspectives offered by the categories of postdramatic theater and performance art, since they place the viewer in an active role, which is assumed as the producer of the work of art. In this sense, a journey is developed in relation to the concept of perception of the subject in the field of theatrical art to discuss it in close connection with the artistic experience studied.

\section{KEYWORDS}

Contemporary theatre. Travelling theatre. Audience participation. Performance. Perception. 


\section{El CASO de TOdo lo QUe eStá a MI LAdo de FeRnando RubIO ${ }^{1}$}

El presente paper es resultado de la investigación denominada TEATRO POSDRAMÁTICO Y ARTES PERFORMATIVAS en Argentina 2010-2020, enmarcado dentro del Núcleo de investigación Centro de Estudios de Teatro, Educación y Consumos Culturales (TECC) en Argentina. El grupo tiene como objetivo relevar experiencias artísticas contemporáneas producidas en regiones metropolitanas del país, durante la segunda década del siglo XXI.

En este artículo se estudian algunos elementos del teatro posdramático que pueden observarse en la obra Todo lo que está a mi lado de Fernando Rubio. La obra, que se estrenó el 2 de febrero de 2012 en Punta Arenas, Chile durante el Festival Cielos del Infinito, también fue presentada como una pieza de teatro performático en el Festival Estival de San Martín de los Andes- Argentina, desarrollado desde el 20 al 31 de enero de 2017. En esa oportunidad, el espacio seleccionado para realizar la presentación fue el Parque Nacional Lanín de la Comunidad Mapuche Churruhuinca, en la ruta 40 a la altura de Pahiúen. La autoría y dirección es de Fernando Rubio, la asistencia de dirección a cargo de Verónica Pellegrini. El elenco para la presentación mencionada se conforma por Ana de Ezcurra, Edith Gazzaniga, Eleonora Arias, Maria Emilia Montalvo, Sofía Verónica Vintrob, Verónica Marí, Viviana Perrone, Sandra Monteagudo (Ruggero Carlos, 2017).

La performance Todo lo que está a mi lado transcurre en distintas camas de dos plazas que se ubican en un espacio natural o urbano seleccionado por el director, en este caso el Parque Nacional Lanín. En cada somier se encuentran acostados, una actriz y un espectador que comparten una escena durante doce minutos. En palabras de Rubio, la idea fundamental para realizar la experiencia nace con un recuerdo de la infancia que lo llevó a tomar la decisión de que el espacio fuese una cama, con una actriz y que el espectador llegara allí a acostarse (RT en español, 2018) En la performance todas las actrices narran la misma historia, contada en segunda persona, de modo tal que involucra directamente al espectador. Al respecto el director afirma: "La obra habla de todas las posibilidades que tenemos de vincularnos con lo desconocido, establecer un contacto muy profundo con alguien que quizás nunca más vuelvas a ver” (Onassis Foundation, 2015: min. 4:55).

El trabajo de Fernando Rubio se destaca, desde 1998, por desarrollar diversos proyectos escénicos que buscan la reformulación del teatro. Específicamente focaliza su indagación en la alteración del uso de conceptos como el espacio y el vínculo con los espectadores, que, concebidos desde una mirada contemporánea, transgreden la perspectiva dramática. De este modo diseña una estética impregnada del cruce de disciplinas y la relación entre el arte, la estética, lo social y la política.

La presentación de la obra Todo lo que está a mi lado se puede conceptualizar dentro de la categoría de teatro posdramático. La propuesta artística es presentada en un formato que puede leerse de diferentes maneras, una de ellas responde a la performance, otra puede definirse como intervención o teatro de invasión y, al mismo tiempo, se la puede ubicar en la categoría de teatro de un sitio específico.

Los rasgos singulares sobre los cuales nos interesa detenernos apelan, por un lado, a la organización de la performance en cuanto a obra itinerante y evento rizomático, ya que existe una lógica de repetición sobre la base del texto, creado a partir de la primera exploración en el espacio público, y la disposición de las camas en cada lugar de presentación. Mientras que los elementos variables están constituidos por la audiencia, que siempre se renueva; por el espacio a intervenir, que es seleccionado para cada presentación por el director; y por las actrices, oriundas de cada lugar. Y, por otro lado, nos interesa detenernos en el rasgo de la experiencia del espectador, como acontecimiento fundante de la definición del hecho teatral, y

1 Fernando Rubio. 1975, Buenos Aires, Argentina. Actualmente reside y trabaja entre Rio de Janeiro y Buenos Aires. Director, dramaturgo, actor y artista visual. Egresado de la Escuela Metropolitana de arte dramático. Director del proyecto de residencias artísticas El Jardín Sahel. Fundador y director de INTIMOTEATROITINERANTE. Profesor durante el año inaugural de la maestría en Artes Performáticas de la Universidad Nacional de Arte. 
como proceso perceptivo del sujeto en un entorno específico. En este caso, caracterizado tanto por el espacio abierto y natural del Parque Nacional Lanín, como la relación de proximidad que se establece con la performer.

Atendiendo a estas consideraciones surge el siguiente interrogante. Si la obra, que admite ser determinada entre las especificidades de la categoría de teatro posdramático, es presentada en espacios públicos que intervienen la dinámica de la vida cotidiana y, al mismo tiempo, proponen un encuentro de extrema intimidad entre la performer y el espectador ¿Cuáles son los elementos teatrales que se emplean en la intervención de este espacio público para generar la inmersión del espectador en una escena de intimidad extrema?.

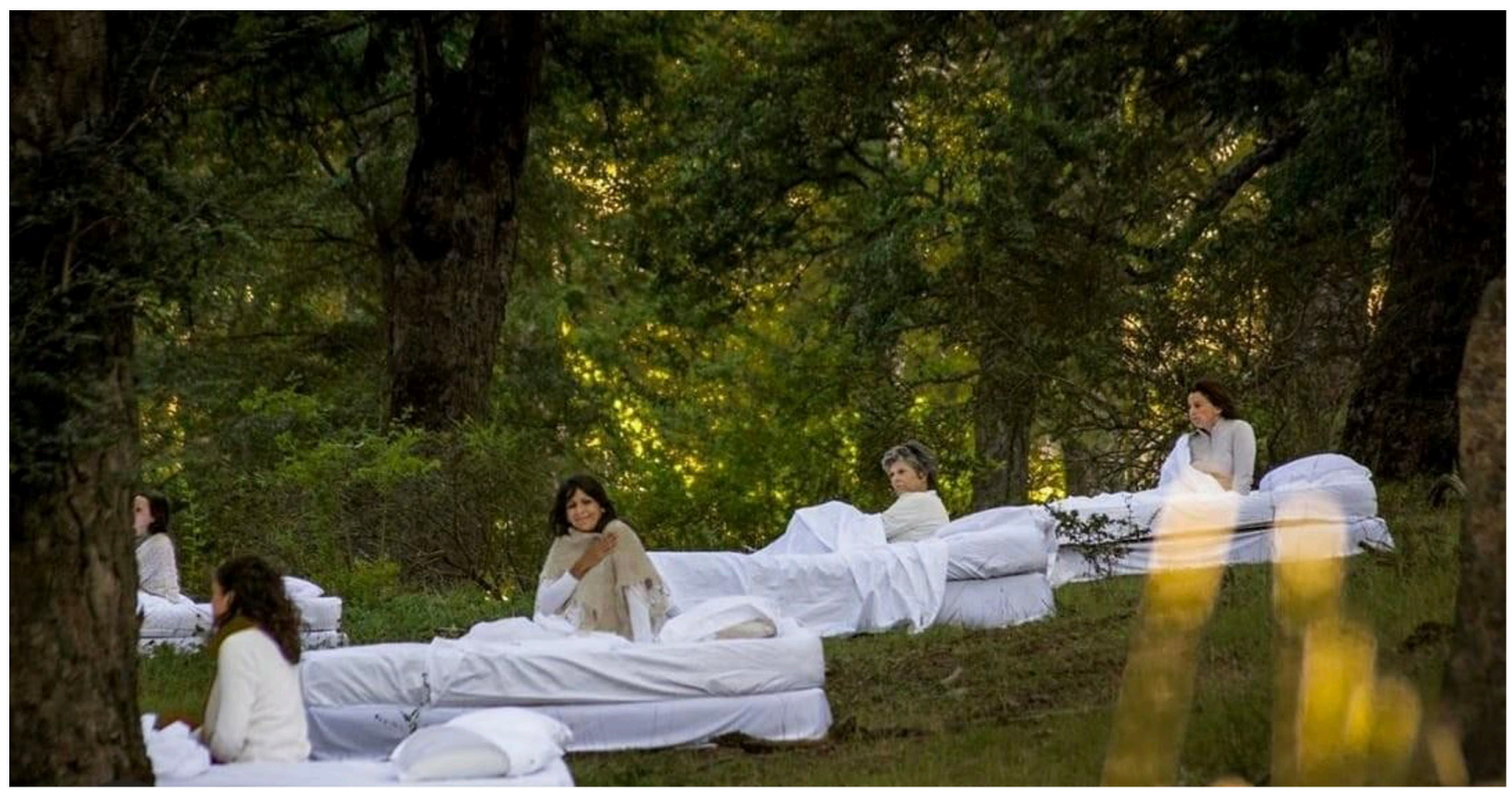

Figura 1: Ricaurte, Rocío (2020) Todo lo que está a mi lado. Festival Estival

\section{UNA PROPUESTA POSDRAMÁTICA}

El interés de abordar esta propuesta de Fernando Rubio se fundamenta en los lineamientos que definen su trabajo, ya que como director busca hacer teatro de una forma diferente, sin respetar una estructura de sala y por consiguiente sin presentar una propuesta de teatro dramático.

La noción de teatro posdramático supone la transgresión de algunos aspectos del teatro dramático, porque "muestra una renuncia a tradiciones que refieren a la forma dramática” (Lehmann, 2013: 43) Lehmann plantea que el desarrollo dramático en el teatro se da desde el siglo XVI al XX, porque el drama se apoya en un modo de teatro europeo y en un concepto que está estrechamente ligado a la noción de subjetividad.

El drama de la época moderna, según Peter Szondi (2001) surgió en el Renacimiento para "presentar la audacia espiritual del hombre de construir la realidad de la obra en la cual se quiso reflejar", es por ello que, como miembros de una comunidad tomaron como punto de partida la reproducción de las relaciones intersubjetivas. Las mismas existen a través del medio lingüístico que está dado por el diálogo y que constituye el único componente de la escritura dramática. 
El dominio absoluto del diálogo en el drama demuestra que el drama consiste sólo en la reproducción de las relaciones intersubjetivas, como Szondi aclara, el drama es una dialéctica cerrada en sí misma, pero libre y redefinida en todo momento. Partiendo de esta cuestión es que Szondi dice que "O drama é absoluto. Para ser relação pura, isto é dramática, ele deve ser desligado de tudo o que the é externo. Ele não conhece nada além de si” (p. 30) Desde entonces, el drama moderno le da significación a un cosmos ficticio, la creación de un mundo a través de la imitación y una separación entre actor y espectador. Este último contempla la escena en una actitud pasiva. Se establece dentro de la escena una relación dialógica entre la forma y el contenido, y es allí donde reside la característica más importante del drama, su carácter absoluto. Szondi (1965, 2001) afirma que el drama es absoluto, mediante el dominio del diálogo que se da en la comunicación intersubjetiva y en relación al trabajo del actor respecto del espectador, porque el diálogo tampoco es una alocución dirigida al público, sino que el espectador se encuentra pasivo frente al drama, en identificación con el espectáculo.

La forma del escenario creada para el drama del Renacimiento también es adecuada al carácter absoluto del drama, porque se hace visible al comienzo y al final del acto escénico. Mientras que en el transcurso de la acción la apariencia de la escena parece funcionar como un todo en sí mismo, como un sistema absoluto. Szondi dice que "O entorno espacial deve (assim como os elementos temporais) ser eliminado da consciência do espectador. Só assim surge uma cena absoluta, isto é, dramática. Quanto mais freqüentes são as mudanças de cena, tanto mais difícil é esse trabalho." (p.33)

Mientras que el estudio del teatro posdramático se ocupa de la realidad escénica tal como fuera esbozada por las prácticas neo vanguardistas en la década del sesenta del siglo XX. A mediados de 1960 surge una forma experimental caracterizada por la formación de comunidades artísticas. Ellas están compuestas por representantes de las distintas disciplinas que tratan de transgredir las fronteras de cada una, y proponen concepciones de espectáculos en los que el público participa e interactúa de modo directo y real con el trabajo que se da en la escena.

Esta nueva concepción del teatro crea su propio discurso, se desdobla según Lehmann, para referenciar lo real. En este sentido se dice que problematiza la realidad "como realidad de los signos teatrales" que poseen un significado determinado. Propone el abandono del pretendido significado único, transparente, de los signos teatrales y obliga al espectador a tomar una postura respecto de la ausencia de significado, entre no pensar en nada o leer las formas tal como se presentan (p.98).

De esta manera, la presentación de la escena posdramática realza la cuestión de fugacidad y convivialidad del hecho teatral. La atención recae en el punto que refiere a la escenificación como momento único en el que se concretiza la obra.

En el teatro posdramático "existe una tendencia al solipsismo" (p.146) porque necesita de una recepción individualista donde prime la diferencia, y en el intento de crear comunidad se comparta y comunique algún punto de vista común con un grupo.

La obra Todo lo que está a mi lado se inicia cuando el director selecciona un espacio no convencional donde armar y presentar la performance, en este sentido se observa que desde el punto de partida hay una concepción posdramática del teatro, porque no se propone estar sujeto a la representación de un texto dramático, sino que Rubio, invita a generar una creación conjunta con las actrices en las inmediaciones del espacio público, previamente seleccionado. Por lo cual, puede decirse que esta propuesta renuncia a la elaboración previa de un texto dramático y decide servirse de los elementos del espacio que funcionan como disparadores para la creación escénica. En cuanto a la reposición de la propuesta, se destaca la continuidad del texto producido desde el espacio público y la intimidad de una cama. En tanto que la variación se da en la elección del espacio público y la conformación del elenco.

La focalización que el director elabora sobre el acontecimiento teatral (Dubatti, 2011) y puntualmente las transformaciones que suceden sobre el sub acontecimiento de la expectación, permiten establecer una relación directa con la subcategoría del teatro posdramático que atiende a las prácticas liminales denominadas "performance", sustentándose también en los testimonios del director Rubio cuando menciona que "la obra es presentada en formato de performance, lo cual permite intervenir espacios urbanos con escenas de absoluta intimidad" (Redacción. 6 de febrero de 2017. Rio Negro "Cartografías imaginarias").

Si bien abordar el concepto de performance es complejo porque, según lo expresa Diana Taylor (2011):

La performance es un término ambiguo ya que no tiene un equivalente en español que implica necesariamente un proceso, práctica, acto, episteme, evento, modo de transmisión, desempeño, realización y medio de intervención en el mundo. En Latinoamérica es utilizado para describir ciertas prácticas artísticas que se caracterizan por ser un arte de acción, "dramas sociales" (Turner: 1986) o "prácticas corporales". También el vocablo se traduce como "ejecución o actuación" (Bauman: 1977) Desde el área artística es entendida en la línea del "arte del performance como práctica estética que tiene sus raíces en el teatro, las artes visuales, el surrealismo o tradiciones performáticas anteriores, como el cabaret y el periódico en vivo (...) es un producto vanguardista cuyos orígenes están en Europa y los Estados Unidos (p. 18)

Al mismo tiempo, Taylor afirma que la performance "surge para romper los lazos institucionales y económicos que excluían a artistas sin acceso a teatros, galerías y espacios oficiales o comerciales de arte" (p.8) De esta manera el artista se expresaba en cualquier espacio y el acontecimiento artístico se manifestaba como una intervención en los circuitos culturales legitimados. Son prácticas que van más allá de los límites artísticos, que combinan elementos políticos y sociales para crear algo inesperado y sorprender al espectador.

Así mismo, el arte de la performance se define como componente del posmodernismo porque "subvierte el 
supuesto modernista de que los significados fijos pueden determinarse mediante la estructura formal de la obra" (Jones. En Taylor y Fuentes; 2011: 127) Respecto del campo teatral Taylor y Fuentes comentan la necesidad de abandonar las características del drama para efectuar el abordaje del performance, afirmando que "desde el punto de vista teatral y experimental, afín a Schechner, la performance permite atender al comportamiento corporal y así desplazar al texto escrito de su lugar central en la producción teatral" (p.34) También Josette Feral (2016-2017) explica que "la performance valora la acción en cuanto tal, por encima de su valor de representación, en el sentido mimético del término [...] La diferencia en este caso [en el teatro performativo] es que este hacer es el primero de los aspectos fundamentales de una creación escénica" (p.32).

Al respecto, Claudia Kozak (2012) sostiene que las performances se componen por la producción efímera de sucesos multidisciplinares donde el artista devenido performer ostenta no solo su presencia física, sino también la propia experiencia biográfica interpelando de forma directa al espectador. De igual manera, para Lehmann, "la performance art es un evento artístico que aspira a una experiencia de lo real, es decir que no ofrece una representación, sino que muestran una acción intencionadamente inmediata de lo real" (2013: 237) y aclara expresamente que la presencia, "la intensidad de una comunicación cara a cara" (p.242) es la característica fundamental que la performance comparte con el teatro.

La propuesta performática aquí presentada interpela directamente al espectador que, deliberadamente selecciona una cama, se acuesta y establece un contacto "cara a cara" con la actriz. El espectador, devenido performer no tiene permitido tocar a la actriz ni entablar un diálogo con ella, pero acciona desde el comienzo con la elección del lugar que va a ocupar, es decir la cama en la cual se acuesta y en la que es interpelado por la actriz. Puede decirse que la reducción de la distancia habitual entre actor y espectador y, por consiguiente, la extrema aproximación de los cuerpos presentes, no dejan escapar la atención de ambos y propician un estado de inmersión que hace efectiva la vivencia de lo real. Para el director Rubio, es fundamental trabajar desde la perspectiva de la performance ya que entiende que:

es un modo de hacer que habilita la expansión espacial, temporal y de situaciones estéticas, de las formas tradicionales que precisan ciertas normas ligadas al espectáculo como cuánto debe durar una obra, cuál es el ámbito adecuado, qué situaciones pueden ocurrir ahí, de qué manera se expone el cuerpo del espectador. Todo eso, la performance, lo trata, lo cuestiona como uno de sus temas centrales (Redacción. 6 de febrero de 2017. Rio Negro “Cartografías imaginarias”)

En lo que se refiere a la intervención de un espacio no convencional, el espacio natural del Parque Nacional Lanín, se entiende que Rubio selecciona los espacios porque se deja influenciar por ellos, parafraseando a Carreira (2017) se dice que la performance exige considerar ese espacio más allá de su potencial escenográfico, ya que el fenómeno escénico se suma al acto social que allí acontece (p.57) por lo cual, al recorrer el parque los espectadores son influenciados por el medio natural, que produce sentido al esta- blecer condiciones de recepción particulares; y al mismo tiempo, ese espectador es interpelado por el contraste de los somier con ropa de cama blanca, con la presencia de las actrices. Además, este espectador puede ver las reacciones de los demás espectadores. Esta particularidad de visionar parte del dispositivo que en teatro dramático queda vedado a la audiencia, es considerada como elementos dramatúrgicos que, según Carreira, se incorporan a la performance de manera no controlada por el proyecto de puesta en escena. De tal modo, puede decirse que la escena ocurre en diálogo con el ambiente, o más precisamente con el experimentar del ambiente como significante del acontecimiento escénico (Carreira. .6o) que contribuye y complejiza la propuesta de las actrices. También se acerca a la definición de teatro ambiental (Schechner, 1994:19) cuando explica que existe una especie de experiencia de entrar y salir que, al ampliar su capacidad de lectura, le permite al espectador redimensionar su lugar en el acontecimiento escénico.

Lo que Rubio representa con sus obras es la condición real de las relaciones (González, en Rubio 2012) Mediante una posición política comprometida con la realidad social contemporánea, lo cual constituye otro rasgo característico de su producción artística, aborda situaciones muy íntimas que hacen centrar la mirada en el encuentro cuerpo a cuerpo con el espectador (Centro Cultural Kirchner, 2015). Generalmente, Fernando Rubio trabaja con límites contrapuestos: en espacios abiertos, busca encuentros de una intimidad extrema y potente entre los espectadores y las actrices. Puede decirse que los trabajos que realiza son interdisciplinarios, ya que en ellos dialogan el teatro, las artes visuales y el espacio urbano o natural. Su trabajo se manifiesta en el formato de la intervención urbana, la instalación y la performance (Televisión Pública, 2013) Rubio comenta en su web que trabaja sobre la posibilidad de construir un tejido de vinculaciones entre lo espacial y lo humano, antes no percibido. Busca resignificar el espacio en que nos encontramos para establecer nuevas afectividades entre conocidos y desconocidos.

Según Eduardo Pavlovsky (En Rubio 2005- 2011) el teatro de Rubio aborda "los temas de la perdida, la soledad, la voluntad de continuar a pesar de todo, la intuición, la sospecha y cuestionamiento a una voluntad mayor que excede la hombre, la idea de Dios, el vínculo entre el hombre y la esperanza aunque habitemos el horror" (Rubio; 2012: 122) estos temas junto a la decisión política de emplear la interdisciplina y diferentes formatos hacen de sus obras conformen "un teatro que pone en riesgo al actor y al espectador y, por ende, un teatro para espectadores que deciden arriesgarse" (p.123).

Otro aspecto a considerar como rasgo fundamental de la propuesta artística, que también se enmarca dentro de la categoría de teatro posdramático, es el carácter itinerante de la obra, lo cual le brinda a Rubio la posibilidad de "leer una misma obra a través de gente del lugar, de actrices que conocen en profundidad y que tienen una relación directa con los espacios". Todo lo que está a mi lado se ha presentado desde entonces en distintos países manteniendo la estructura formal y conceptual, sin embargo, lo que está en un cambio constante es el espacio y el elenco, a lo cual Rubio agrega que "es la posibilidad de leer una misma obra a través de gente del lugar” (Ruggero Carlos, 2017) 
Cabe aclarar que las actrices mantienen la centralidad del texto al reproducir, todas, el mismo parlamento. Este aspecto es considerado porque a Rubio le interesa "trabajar con esa idea de una voz que se replica en diferentes cuerpos" (Ruggero Carlos, 2017) En el breve texto creado desde la acción escénica, se aprecian momentos que denotan una "historia que atraviesa la inocencia, el crecimiento, la perdida y el alivio después de la perdida":

Hubo un momento en que creciste, soñaste que todo lo que estaba por delante era poderoso, confiable y es taba vivo. Tuviste la sensación de inspirar la fuerza de todo lo que te rodeaba, de todos los que estaban a tu lado (Rubio, 2012: 87)

A este estilo de obras, con intervenciones urbanas y de carácter itinerante, el teatro posdramático las contempla desde la idea de "Teatro de un lugar específico" (Theatre on location) (Lehmann, 2013: 295) que tiene entre sus finalidades expandir el teatro a lugares no habituales para captar al público local. Lehmann dice que en el Site specific theatre, "el sitio se muestra con una nueva luz (...) y origina una nueva mirada estética en la que el espacio y los espectadores son co- actores" (p.296) Es una situación espacial, de carácter comunitario que propicia la experiencia ritual de la performance art.

\section{EL ACONTECIMIENTO DE LA EXPECTACIÓN:}

Al menos dos tipos de definición expresan la especificidad del teatro: una definición lógico- genética, como acontecimiento triádico, y una definición pragmática, como zona de experiencia y construcción de subjetividad. Según la redefinición lógico-genética, el teatro es la expectación de poíesis corporal en convivio; según la definición pragmática, el teatro es la fundación de una peculiar zona de experiencia y subjetividad en la que intervienen conviviopoíesis-expectación. Esta última definición, como Dubatti sostiene en Filosofía del Teatro I, implica la superación de los conceptos de "teatro de la representación" y "teatro de la presentación", en tanto regresa la definición del teatro a la base convivial y viviente del acontecimiento.

Por lo tanto, recuperar la centralidad del encuentro de cuerpos presentes y la experiencia perceptiva de ese acontecimiento, reconfigura la noción de teatro y permite ubicar los sub acontecimientos de acción, expectación y tiempo-lugar en igual plano de importancia. Este retorno a la base convivial recupera, además, la atención en el flujo de influencia entre la audiencia y la acción poética que crea el actor. Ya que la influencia o la retroalimentación del actor y el espectador es lo que completa y crea la obra teatral. Al respecto, nos detendremos en este rasgo característico del trabajo de Rubio, que se ocupa de generar una idea renovada del teatro sobre la base del trabajo con el espectador.

La idea inicial de Rubio para crear Todo lo que está a mi lado se basa en buscar la "resignificación del lugar del espectador y encontrar en el cuerpo del espectador una manera más de pensar el teatro" (Onassis Foundation, 2015: min. 1:48). Esa necesidad de atravesar la experiencia, de vivenciar el acontecimiento en ese lugar específico, hace que el espectador activo deje de estar en el espacio de butaca compartiendo un fragmento de temporalidad y visionando el espectáculo, para habitar la escena y resignificar ese espacio no convencional intervenido por la performance. Es decir que, "el espectador pasa a estar inmerso en el escenario y en interacción directa con la performer” (Lehmann, 2013: 188). Ese rol, es lo que garantiza que el espectador cargue de significación la escena percibida a través de su imaginario.

Si Dubatti (2011) indica que un "acontecimiento teatral se constituye en tres sub acontecimientos: el convivio, la poiesis, la expectación" (p.35) donde "confluyen tramas paralelas que coexisten en su heterogeneidad y a la par se fusionan en el cuerpo poético": mencionando la presencia de materiales de la realidad cotidiana, la presencia metafísica, el trabajo como materia sea físico o interno (mental o emocional) (2014: 29) Es en la obra seleccionada donde se complejiza e intensifica la definición de acontecimiento teatral expuesta, ya que modifica uno de sus aspectos introduciendo una variante en el sub acontecimiento de la expectación.

La expectación en el espacio escénico tradicional o dramático, se desarrolla en el momento en que el espectador está ocupando el espacio de butaca. Cuando comparte la experiencia de ser espectador su presencia se configura como influencia y, a la vez, es influenciado por los otros espectadores presentes en la sala. La proximidad con el otro que especta produce una afectación en su percepción. De manera que, los gestos y sonidos emitidos por todos los 
presentes en la sala aportan rasgos de significación que la audiencia condensa al darle sentido a la obra desde su propio imaginario. Entonces, puede decirse que la conformación de esa platea diversa define el sub acontecimiento de la expectación como suceso único y efímero.

Sin embargo, en el caso de Todo lo que está a mi lado, como el título lo indica, cada espectador es forzado a abandonar ese lugar de encuentro con las otras personas que espectan para tener un encuentro, más cercano y de gran intimidad, con la performer. El sujeto abandona la sala teatral y se dispone a transitar una experiencia en un espacio abierto y conocido en otro contexto, como es el caso del Parque Nacional Lanín. También, deja la comodidad de la butaca para habitar la serenidad de la cama en una postura horizontal. Casi como una entrega, el espectador se recuesta y se sumerge a la vez en un universo nuevo, dónde es rodeado por la textura de las sábanas y la almohada, por la presencia de ese espacio inmenso como el bosque y el cielo de San Martín de los Andes, y por la presencia inmediata de la performer que acciona susurrando textos al espectador.

Todas las características que se han mencionado confluyen en la consideración de un concepto fundamental sobre el que incide la variable de expectación, elaborada y trabajada desde Todo lo que está a mi lado. Ese concepto es la percepción, entendido como la relación que se establece entre lo interno y externo del ser que habita un entorno.

Dentro de lo que puede definirse como la percepción, Merleau Ponty (1997), dice que la cosa y lo real son definidas mediante la experiencia de percibir con el cuerpo y el intelecto la totalidad: "Llamo experiencia de la cosa o de la realidad- una realidad absoluta- a mi plena coexistencia con el fenómeno, al momento en que este estaría, bajo todos los aspectos, al máximo de articulación" (p.332) En este sentido se refiere a la pluralidad de aspectos, miradas y sentidos que atraviesan la noción de completitud de la cosa y la realidad, emparentada a la idea de Adorno que versa sobre lo incapturable de la realidad. Merleau Ponty dice, "lo que se ofrece nada más que a uno de mis sentidos, es un fantasma y no se aproxima a la existencia real más que si deviene capaz de avalar a mis demás sentidos" (p.332)

Para Ponty, es el ser humano desde su corporeidad que define las cosas y la realidad "la cosa es la plenitud absoluta que mi existencia indivisa proyecta delante de sí misma” (p.333) De esta manera, al darse la relación entre las cosas y el cuerpo existe siempre una mediación generada por el propio cuerpo, que al pensarlas se les da existencia. Es también una relación simbiótica, porque es en virtud de ese contexto creado, definido a través de la percepción que se determina el propio cuerpo y la subjetividad: "Una cosa no se da efectivamente en la percepción, es recogida interiormente por nosotros, reconstruida y vivida por nosotros en cuanto vinculada a un mundo, del que llevamos con nosotros las estructuras fundamentales" (p. 340)

Considerando que el individuo a través de su experiencia le asigna significado a los objetos y a su entorno (Gutiérrez, Plaza Suñiga y Campuzano, 2020) y que de esta manera construye una realidad y la habita, es que puede establecerse un paralelismo con el campo teatral en lo que refiere al suceso escénico. Se entiende que el actor, a través de su acción crea otros mundos, genera lugares en espacios ya conocidos y funcionales a eventos cotidianos que no necesariamente son de índole artística. La transformación de ese espacio cotidiano en un "otro lugar" se da gracias a la predisposición perceptiva y a la aceptación de algunas convenciones (Pavis, 1994) dadas en ese encuentro, de espacio y tiempo, compartido entre el actor y el público. Ese espacio no sólo contiene la escena, sino que dialoga con ella hasta fundirse y formar un todo. Al respecto, Fernando Rubio observa sobre Todo lo que está a mi lado: Si lo que rodea al sitio donde se ubican las camas, tiene una historicidad, está en reflexión permanente. No solo se tiran las camas y da lo mismo donde sea (Redacción. 6 de febrero de 2017. Rio Negro "Cartografías imaginarias").

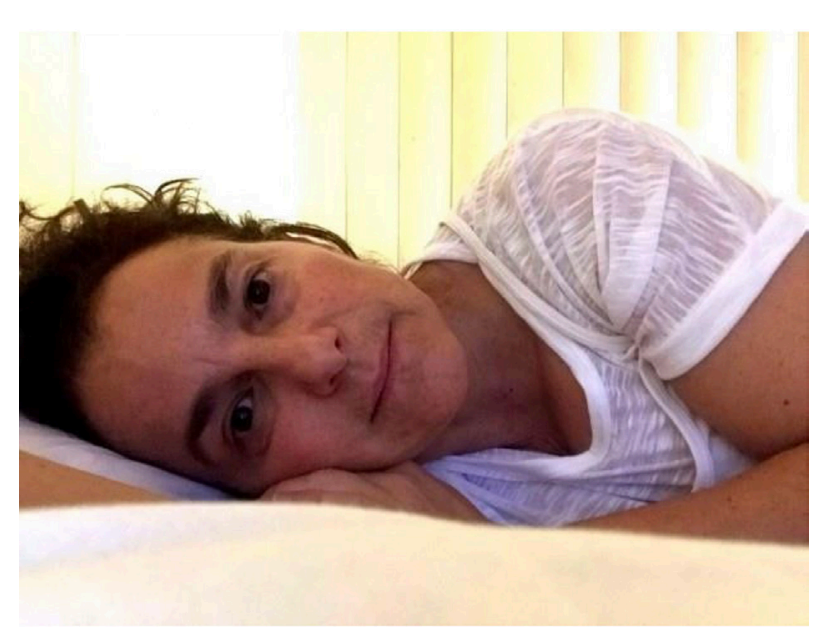

Figura 2: Ricaurte, Rocío (2020) Sandra Monteagudo. 


\section{ENTORNO Y NUEVAS AFECTIVIDADES}

En el campo del arte escénico es mediante la experiencia estética que tanto el actor como el espectador del teatro contemporáneo desarrollan una relación simbiótica al habitar un espacio concreto. En el transcurso del acontecimiento ambos perciben el entorno para dejarse influenciar por él, con sus signos y sonidos explícitos y sugerentes; $y$, al mismo tiempo, el bagaje cultural del actor y espectador les permite otorgar significación a ese contexto específico. Vale decir que, todo individuo involucrado en este planteo, actor y/o espectador, establece valoraciones en relación a la percepción de imágenes propuestas desde el medio escénico y el espacio teatral o urbanos/naturales donde se desarrolla la obra $(G o ́ m e z, 1997)$ para enfrentarlas y/o complementarlas con las significaciones de su propia historicidad. Al respecto se cita la referencia que Gutiérrez, Plaza Suñiga y Campuzano (2020) mencionan en su investigación poética:

Al referirnos a la imagen-mundo establece que las palabras definen propiedades de los objetos que se pueden calcular e interpretar. El sujeto-objeto es entonces un cuerpo de propiedades singulares en el que se puede percibir lo subjetivo del objeto y la objetualidad intrínseca a los sujetos (p. 88)

El sujeto-objeto que habita un espacio, es el que lo define, pues tiene la potestad de hacerlo mediante la conceptualización. Ese proceso, supone un acto de percepción del entorno y de los objetos que resuenan en el interior del sujeto. Del mismo modo que lo propone Merleau Ponty, su reacción permite definir esa imagen-mundo exterior, y también, le brinda la posibilidad de autodefinirse interiormente y en relación al contexto. La experiencia de percepción generada al habitar una escena teatral persigue la misma finalidad en el espectador, es decir que, tiene por fundamento reanimar y potenciar la capacidad perceptiva del espectador.

Todo lo que está a mi lado potencia y amplifica la experiencia convivial y de acción poética desarrollada por cada performer. Para lograrlo, desde la dirección Rubio emplea diversas estrategias: La primera puede considerarse como la expansión del espacio teatral ubicando al espectador de teatro en un espacio que no sea un teatro, donde no imperan las convenciones conocidas por los que frecuentan el ambiente. Para ello la nueva localización es lograda a través de la intervención de un espacio natural, el Parque nacional Lenin. Otra estrategia es configurada por el aislamiento de cada espectador, lo cual le permite intensificar el acontecimiento escénico con la presencia física cuerpo a cuerpo. Y, por último, la ubicación o disposición del espectador respecto del espacio escénico, en este caso la cama de dos plazas donde los sujetos se acuestan y modifican tanto su relación con el entorno como la perspectiva de lo que se percibe.

En el intersticio propuesto desde Todo lo que está a mi lado el sujeto espectador es atravesado por múltiples disparadores que estimulan profundamente todos sus sentidos, que lo obligan a estar presente, percibiendo la actua- lidad del entorno, del otro sujeto que acciona poéticamente y de su propia existencia.

Gutiérrez, Plaza Suñiga y Campuzano (2020) explican que el enfoque del Nuevo Realismo "a grandes rasgos plantea la posibilidad de que un sinnúmero de objetos pueda existir indistintamente de un sujeto" (p. 88) Es decir que el Parque Nacional Lanín con su vegetación y su fauna existe independientemente de la intervención artística realizada en esta oportunidad, del mismo modo que la cama y las sábanas, y los sonidos allí presentes existen antes que el espacio natural sea habitado por los sujetos. Es por ello que los espectadores y las actrices que realizan la performance necesitan estar en ese parque, para percibir, para descubrir con todos los sentidos el espacio, las imágenes y establecer una relación interna que les permita también estar con ellos mismos, con sus recuerdos e ilusiones.

Los autores, que citan la perspectiva de Markus Gabriel, reflexionan sobre la desaparición de la presencia del yo como dimensión de la existencia en el Nuevo Realismo para afirmar que es

como si el sujeto fuera un objeto más en algunos campos de sentido en las relaciones ontológicas, y que incluso los procesos internos de raciocinio se sumarán a los campos como un objeto más que pertenece al mismo plano que el del sujeto (2020: 90)

Por esta razón las ideas, las sensaciones y el cuerpo como tal son objetos que interactúan con otros objetos en un entorno dado.

Habitar un espacio dejándose influir por la imagen, el sonido, el tacto, el olfato es un acto que implica, además, un movimiento en el espacio y a través del tiempo. Esta experiencia evoca una representación de lo visto y lo vivido, apelando a la historicidad del sujeto y a sus recuerdos que generan la representación de nuevas imágenes. Cuando se producen estos procesos complejos de intercambio entre lo interior y exterior de cada espectador, a través de una relación dialógica con los objetos propuestos por el artista, puede decirse que el sujeto construye la realidad y completa la obra artística

Por lo dicho, se considera que la presentación de Todo lo que está a mi lado es una performance que le propone al espectador habitar la escena y comprometer al máximo su capacidad perceptiva para asumir el rol de "actor fundamental" en el desarrollo de la misma.

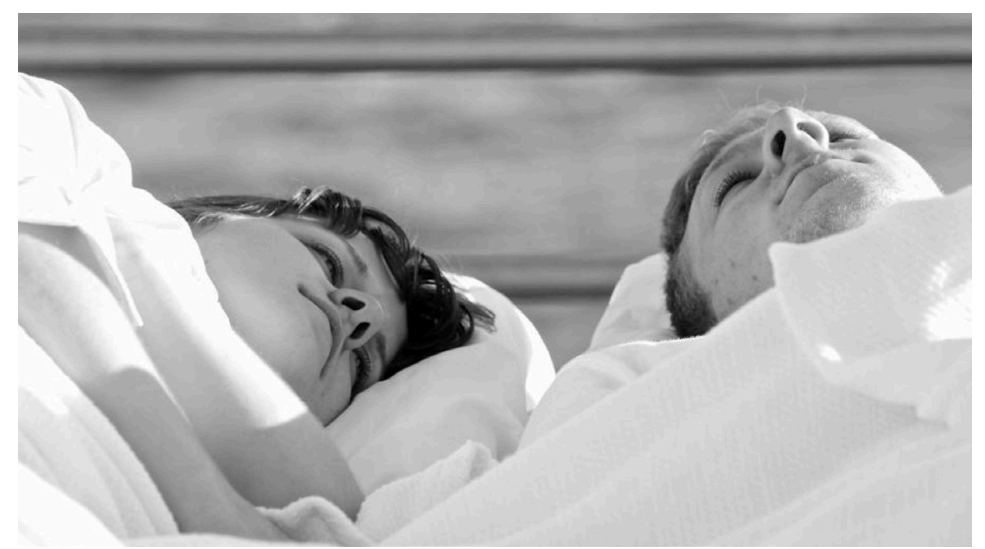

Figura 3: Redacción (2017) Cartografías imaginarias. Rio Negro. 


\section{REFLEXIón}

La experiencia de Todo lo que está a mi lado propone un teatro en el que la percepción se encuentra dominada por la "cercanía del organismo vivo" como lo ha llamado Grotowski (1970) donde la proximidad entre el actor y el espectador es tan estrecha que toma supremacía la percepción fisiológica por sobre la significación racional de la escena.

La performance se transforma en un ritual de 12 minutos que requiere la participación y el compromiso emocional del espectador que comparte la vivencia orgánica con el actor.

El espacio total, el medio natural en el que se desarrolla abandona la propuesta dramática de simbolizar un mundo entendido como totalidad, para mostrar un fragmento de la realidad de la vida. En este sentido, se considera una propuesta que expande el teatro a lugares no habituales, porque ocupa un lugar particular para la ciudad e invita a los habitantes a compartir la actuación. Se ha ubicado a Todo lo que está a mi lado dentro de la categoría de teatro posdramático y específicamente dentro del Site specific theatre, lo cual significa que el sitio se muestra bajo una nueva luz, una nueva perspectiva. El lugar natural o urbano se hace visible y con él, la comunidad que lo habita. Parafraseando a Lehmann, es una situación comunitaria donde se experimenta el teatro como tiempo compartido, como experiencia conjunta. Es la necesidad de intensificar el momento en el cual sucede ese encuentro en el espacio público, un momento para percibirse allí y también percibir al otro, para reconocerse en él.

Si bien, para la realización de la obra se monta un gran dispositivo de intervención artística, se sostiene que la propuesta es puro acontecimiento, porque se circunscribe a ese encuentro de la actriz que acciona ante un espectador, y que constituye la esencia del teatro. Es un acontecimiento que puede ser materializado en diversos lugares del mundo, en diferentes culturas, con distintas artistas y un público renovado. Es decir que la mayoría de los componentes pueden variar, salvo el encuentro entre la acción de la actriz y la expectación, la prueba de esta afirmación es respaldada por el recorrido por distintos países donde se presentó Todo lo que está a mi lado, por ser traducida a más de diez idiomas y dónde participaron más de trescientas actrices en treinta elencos. Y durante la pandemia, en el 2020 , cuando Rubio presenta la propuesta a través de una plataforma digital pensada para conectar distintos dispositivos a internet y vivenciar la obra a tiempo real. La adaptación que sufre la performance para ser presentada a través de la red refuerza también la singularidad del acontecimiento, ya que existe un encuentro entre la actriz y el espectador, que se da durante una fracción de tiempo y en un espacio virtual. 
CARreira, André (2017). Teatro de invasión. La ciudad como dramaturgia. Córdoba, Argentina. Ediciones DocumentA/Escénicas.

Dubatt, Jorge (2011). Introducción a los estudios teatrales. México. Libros de Godot.

(2014) Filosofía del teatro III. Buenos Aires. Atuel.

GómEZ, JosÉ (1997). Historia visual del escenario. España. La avispa.

GutiérRez, Plaza Suñiga y Campuzano (2020). Habitar la imágen, en busca de lo microinmanente por medio de la poética. En Panambí N 11. Valparaiso. Dic 2020. pp. 85-96. Recuperado de: https://revistas.uv.cl/index.php/Panambi/article/ view $/ 2545$

Feral, Josette (Agosto 2016- Julio 2017). En Investigación Teatral. Revista de artes escénicas y performatividad. Vols 6 - 7. Núms 10-11. Segunda época, pp.25-50. México. Universidad Veracruzana.

Kozak, Claudia (2012). Tecnopoéticas argentinas. Archivo blando de arte y tecnología. Buenos Aires. Caja Negra Editora.

Lehmann, Hans Thies (2013). Teatro posdramático. Madrid. Cendeac- Paso de Gato. MerleauPonty, Maurice (1975). Fenomenología de la percepción. Barcelona. Ediciones Península s.a.

Pavis, Patrice (1994, 2005). Diccionario del teatro. Buenos Aires. Editorial Paidós. Rubio, Fernando (2012). Dramaturgias de la acción: obras para teatro, intervenciones y performances. Buenos Aires. Colihue.

SCheChner, Richard (1994). Performance. Teorías y practicas interculturales. Argentina. Universidad de Buenos Aires.

Szondi, Peter (2001). Teoria do drama moderno (1880-1950) Traducción: Luiz Sérgio Repa. San Pablo. Cosac \& Naify Ediçiones.

TAYloR, D. y Fuentes, M. (2011). Estudios avanzados de performance. México. Fondo de Cultura Económica

\section{REFERENCIAS EN INTERNET:}

Centro Cultural Kirchner (2015, 2 De julio). Fernando Rubio- Obra y autor. Recuperado de: https://www.youtube.com/watch?v=uxuyQ 5 LUgMg

ONASSIS Foundation (2015, 9 DE Julio). Transitions 2. Fernando Rubio: "Everything by my Side". Recuperado de: https://www.youtube.com/watch?v=-|vRnolgClw\&feature=youtu.be

Radio nacional San Martín de los Andes (2020, 1 de julio). "Todo lo que está a mi lado": Teatro intimo, en vivo y por internet. Recuperado de: https://www.radionacional.com.ar/todo-lo-que- esta-a-mi-lado-teatro-intimoen-vivo-y-por-internet

RICAURTE, Rocío (2020, 30 DE JUNIO). Sandra Monteagudo participará en la edición mundial de la obra Todo lo que esta a mi lado. Realidad Sanmartinense. Recuperado de: https://realidadsm.com/2020/06/30/sandra-monteagudo-participara-en-laedicion-mundial-de-la- obra-todo-lo-que-esta-a-mi-lado/ 
Ruggero, Carlos (2017, 16 de febrero). Fernando Rubio "Todo lo que está a mi lado" $16^{\circ}$ Festival Estival de San Martín de los Andes. Recuperado de: https://www.youtube.com/watch?v=PJUPILG3 Is

RT EN Español (2018, 3 DE FEbrero). Entrevista con Fernando Rubio, director teatral y artista visual argentino. Recuperado de: https://www.youtube.com/watch?v=Y2qz1fmOFOs

Televisión Pública (2013, 15 DE ABRIL). Vivo en Argentina- Fernando Rubio, intimo teatro itinerante. Recuperado de: https://www.youtube.com/watch?v=ExyfvFqK1x4

Carlota Guivernau. Todo lo que esta a mi lado de Fernando Rubio. Recuperado de: http://www.carlotaguivernau.com/project/todo-lo-que-esta-a-mi-ladofernando-rubio/

REDACCIÓN (6 de FEBRERo de 2017). Cartografías imaginarias, diario Rio Negro. Recuperado de: $\quad$ https://www.rionegro.com.ar/fernando-rubio-comparte-los-ejes-delpensamiento-performatico-CF2171765/

FernANDo Rubio. Recuperado de: http://fernandorubio.com.ar/mobile/ensayos.php?i=35

Figura 1: Ricaurte, Rocío (2020) Todo lo que está a mi lado. Festival Estival. Recuperado de: https://realidadsm.com/2020/06/30/sandra-monteagudo-participara-enla-edicion-mundial-de-la-obra- todo-lo-que-esta-a-mi-lado/

Figura 2: RicAurte, Rocío (2020) Sandra monteagudo. Recuperado de: https://realidadsm.com/2020/06/30/sandra-monteagudo-participara-en-laedicion-mundial-de-la-obra-todo-lo-que-esta-a-mi-lado/

Figura 3: RedAcCión (2017) Cartografías imaginarias. Rio Negro. Recuperado de: https://www.rionegro.com.ar/fernando-rubio-comparte-los-ejes-delpensamiento-performatico- CF2171765/ 